between the inversion and the bottom relief, and points out that the depth of the inversion rises and sinks in accordance with the semi-diurnal tide. There are probably also seasonal and aperiodic pulsations. An important paper by $W$. Horn gives a concise and partly new representation of the tides as a function of time. G. Tomczak describes a wave gauge, an instrument for measuring short-period oscillations of pressure in the sea, and $\mathbf{F}$. Nusser presents a notable report on ice-conditions on and off the German coasts during the severe winter of 1946-47.

\section{Chemical Prevention of Potato Dry Rot Disease}

As a result of research during the past five years, Bayer Products, Ltd., Crawley Research Station, Brighton Road, Crawley, Sussex, claim to have developed a highly efficient preparation for the prevention of dry rot of potato tubers caused by the fungus Fusarium cceruleum. This preparation, marketed under the trade name of 'Fusarex', is based on 2,3,5,6 tetrachlornitrobenzene, a chemical first described in 1868 by Jungfleish, who prepared it by treating tetrachlorbenzene with fuming nitric acid for some hours at near boiling point. 'Fusarex' is most effective for the control of dry rot when applied to the tubers immediately on lifting, followed by a period of four to six weeks storage in a clamp. It has been found in trials that the preparation does not need to cover each potato completely so long as an even distribution through the mass of tubers is obtained. Thus. a simple manual application can be employed, involving no expense in labour or machinery, and no interference with the normal lifting operations. It has also been found that suitable 'Fusarex' treatment and storage conditions can delay the development of sprouts by the tubers. The treatment of main-crop varieties to prevent sprouting is now a practical proposition; but special techniques are still being worked out for early varieties. Intensive pharmacological tests have shown that tetrachlornitrobenzene is of such a low order of toxicity that it can be regarded as non-poisonous under the conditions of use suggested, and it is therefore safe to use on potatoes destined for human consumption and stock feeding.

\section{Jewels for Instruments}

A REviSED edition of "British Standard 904", first issued in 1940, has recently been published (British Standard $904: 1948$. Dimensions of Instrument Jewels. Pp. 12. (London : British Standards Institution, 1948.) 2s, net). The forms and dimensions of $V$-jewels, ring stones and end stones for instrument purposes, and compass jewels, are specifiəd; and in an appendix the method and apparatus required for the inspection of jewels is described. The Standard does not relate to jewels for watches and clocks, for which a separate British Standard is being prepared, nor to cup jewels for integrating meters, the form of which is still the subject of research.

\section{Sun-Bathing by Birds}

RECENT communications to British Birds have directed attention to the widespread occurrence of the habit of sun-bathing among birds. The question has been raised "whether irradiation of the skin, with its consequent effect of vitamin $\mathbf{D}$ production, could take place through sun-bathing". Prof. W. C. Wynne-Edwards has stated that direct irradiation of the skin is usually impossible in both birds and mammals because of their thick coats. From observ. ations lasting over sixteen years, however, Noble Rollin has collected photographs and information which lead him to the belief that irradiation of the skin takes place among jackdaws, chaffinches, blackbirds, hedge-sparrows and house-martins, although no evidence of sun-bathing has been observed among gulls and wading birds (British Birds, 41, No. 10 ; October 1948).

\section{Science Progress}

Among the articles in the current issue of Science Progress (36, No. 144 ; October 1948) is one which has not only the appeal of a biography of a well-known man of science but also the charm of writing which reminds one of Maurois. This is "Augustin Fresnel: His Time, Life and Work, 1788-1827", by G. A. Boutry, director of the Laboratoire d'Essais, Paris. In the same volume Prof. H. P. Himsworth contri. butes a masterly survey of recent developments in the researches into liver disease, while $\mathbf{E}$. E. Schneider's review of contemporary knowledge of the electronic structure of solids and H. H. Macey's consideration of the theoretical aspects of clay consolidation are supported by an article on the relation. ship between "Indeterminism and the Wish" by J. C. Gregory. The volume also contains the usual summary of recent advances in various aspects of science and a considerable number of reviews.

\section{Proceedings of the Physical Society}

IN order to accommodate the increased number of papers submitted for publication, the Proceedings of the Physical Society is to appear in two parts, $A$ and $B$. Proceedings $A$ will include a contents list of the corresponding Proceedings $B$ and vice versa. Section $A$ will include subjects such as quantum theory, statistical mechanics, nuclear physics and cosmic rays, atomic physies, molecules, spectra, theories of solids. liquids and gases, surface phenomena, growth and properties of crystals, crystal structure, luminescence, electrodynamics, heat and thermodynamics, standards. Section $B$ will include subjects such as acoustics, including ultrasonics, optical design, electron optics, colour, elasticity and other mechanical proper. ties of solids and liquids, crystal structure analysis, magnetic materials, refrigeration and liquefaction, electric discharges, radio, geophysics, including ionosphere, astrophysics, solar physics.

\section{International Congress of Mathematicians}

An International Congress of Mathematicians will be held in Cambridge, Massachusetts, during August 30-September 6, 1950, under the auspices of the American Mathematical Society. It will be open to mathematicians of all national and geographical groups. Harvard University will be the principal host institution. A number of other institutions in Boston will join in the entertainment of Congress visitors. In recent years, mathematicians have been much impressed by the success of the conference method for presenting recent research in fields in which vigorous advances have just been made or are in progress. The 1950 Congress will include conferences in several fields. Following established custom, there will also be a number of invited addresses by outstanding mathematicians. In addition, sectional meetings for the presentation of contributed papers not included in conference pro. grammes will be held in the following fields: I, Algebra and Theory of Numbers; II, Analysis; III, Geometry and Topology ; IV, Probability and 
Statistics, Actuarial Science, Economics ; V, Mathematical Physics and Applied Mathematics; VI, Logic and Philosophy ; VII, History and Education. The official languages of the Congress will be English, French, German, Italian and Russian. Harvard University has offered the use of its dormitories and dining-rooms for mathematicians and their guests for the period of the Congress, and the Organising Committee hopes that it will be possible to furmish board and room without charge to all mathematicians from outside the North American continent who are members of the Congress. Congress membership fees will be announced well in advance of the opening of the Congress. Every effort will be made to facilitate the travel at reasonable cost of foreign participants while in the United States. Communications about the Congress should be addressed to the American Mathematical Society, 531 West 116th Street, New York City 27, U.S.A.

\section{Congress of Comparative Pathology}

The International Congress of Comparative Pathology will hold its fifth meeting in Istanbul during May 17-20, 1949. The Congress covers all aspects of human, plant and veterinary pathology, and considerable latitude is permitted in the choice of subjects for discussion. The British National Committee (chairman, Prof. T. Dalling, Ministry of Agriculture) will be glad to receive, as soon as possible, the titles of communications which members in Great Britain, who hope to attend the Congress, wish to submit for transmission to the Secretaire Générale of the Permanent Committee. Further information can be obtained from Mr. R. E. Glover (honorary secretary, British National Committee), Royal Veterinary College, London, N.W.1, or from Pr. N. R. Belger, Taksim, Siraserviler 75/3, Istanbul.

\section{Commonwealth Fund Fellowships}

THE Commonwealth Fund of New York is offering in 1949 a number of fellowships for British subjects to study in the United States for one year. Twenty such fellowships will be available to British subjects between twenty-three and thirty-five years of age, who are graduates of a university of the United Kingdom or who have studied in one, having previously graduated from a university of Australia, New Zealand or South Africa. In addition there are three fellowships for candidates holding permanent positions in the higher ranks of the Civil Service of Great Britain, and five more fellowships for those in Government service in the Commonwealth. The emolument consists of a total grant of approximately 950 dollars with an allowance of 200 dollars a month plus free travel to and from the United States. Applications must be submitted by February 1, 1949, and full details may be obtained from the Secretary of the Committee of Award, 35 Portman Square, London, W.1.

\section{Royal Meteorological Society: Popular Lectures}

THE Royal Meteorological Society has arranged a series of monthly meetings, to be held at the Science Museum Lecture Theatre, Exhibition Road, South Kensington, and visitors will be welcome. The first meeting, on December 3 at 5.30 p.m., will consist of a film show, and thereafter popular lectures will be delivered at 6 p.m. by the following speakers on the dates shown: Sir George Simpson, January 12; Sir Nelson Johnson, February 10; Prof. Gordon
Manley, March 3 ; Dr. G. M. B. Dobson, April 6; Mr. E. Gold, May 5.

\section{University of London: Appointments}

THe following appointments in the University of London have been announced. Dr. Dennis Gabor has been appointed to the Mullard readership in elec. tronics tenable at the Imperial College of Science and Technology, London, as from Januạry 1, 1949. The title of reader in the University has been conferred on the following: Dr. Vera Fretter, lecturer in zoology at Birkbeck Collegə; Dr. P. A. I. Gorer, of the Department of Experimental Pathology, Guy's Hospital Medical School ; Dr. G. E. Newell, lecturer in zoology at Queen Mary College.

The degree of D.Sc. has been conferred on Mr. E. J. Popham, an external student.

\section{The Night Sky in December}

Fuxl moon occurs on Dec. 16d. 09h. 11m. U.T., and new moon on Dec. $30 \mathrm{~d} .09 \mathrm{~h} .44 \mathrm{~m}$. The following conjunctions with the moon take place: Dec. 2d. $16 \mathrm{~h}$., Jupiter $4^{\circ}$ N.; Dec. 2d. 17h., Mars $3^{\circ}$ N. ; Dec. 21d. $09 \mathrm{~h}$., Saturn $3^{\circ}$ S.; Dec. 28 d. $06 \mathrm{~h}$., Venus $4^{\circ}$ N. ; Dec. 31d. 19h., Mars $4^{\circ} \mathrm{N}$. In addition to these conjunctions with the moon, Mars is in conjunction with Jupiter on Dec. ld. 08h., Mars $1 \cdot 1^{\circ} \mathrm{S}$. Mercury rises at $7 \mathrm{~h}$. $15 \mathrm{~m}$. on Dec. 1 , or nearly half an hour before sunrise, but is too close to the sun for observation, and is not favourably placed for observation during the month. Venus is a morning star, rising at $4 \mathrm{~h} .40 \mathrm{~m} ., 5 \mathrm{~h} .23 \mathrm{~m}$. and $6 \mathrm{~h} .09 \mathrm{~m}$. at the beginning, middle and end of the month, respectively. The magnitude of the planet is $-\mathbf{3} \cdot 4$ during December, and the visible portion of the illuminated disk varies from 0.84 to 0.90 . Mars is still too close to the sun for favourable observation, setting less than an hour and a half after the sun throughout the month. Jupiter is also too close to the sun to be well observed, and is in conjunction with the sun on Jan. 1. Saturn, in the constellation of Leo, rises about $23 \mathrm{~h}$. on Dec. 1 and 21 . on Dec. 31 ; it is visible throughout the morning hours in the early part of the month and also during the later hours of the night in the last part of the month. The planet is stationary on Dec. 17. No oceultations of stars brighter than magnitude 6 take place during December. Winter solstice occurs on Dec. 21d. 23h.

\section{Announcements}

DR. W. CAMPBELL SMITH, keeper of the Department of Mineralogy in the British Museum (Natural History), has been appointed to the new post of deputy chief scientific officer in the Museum; he will retain his post in the Department of Mineralogy. Dr. Maurice Burton has been appointed a senior principal scientific officer (deputy keeper) in the Department of Zoology.

THe following appointments have been made in the University of Leods: Mr. W. J. Thomas, as lecturer in agricultural economics; Dr. A. D. Walsh, as lecturer in inorganic and physical chemistry.

THe following have been appointed officers of the Society for Visiting Scientists, 5 Burlington Street, London, W.1: President and Chairman, Sir Harold Spencer Jones ; Secretary, Prof. F. J. M. Stratton; Treasurer, Mr. H. R. Walters. 